\title{
Ser, percepción y presencia
}

\author{
Being, Perception and Presence
}

Resumen: El presente escrito pretende dar cuenta de algunos aspectos decisivos de la filosofía transcendental kantiana y de su lectura fenomenológica por Heidegger. Se centra en la denominada "tesis de Kant sobre el ser" con el propósito de situar la exposición en un marco explícitamente ontológico y de esbozar una cierta comprensión de los fenómenos de finitud y transcendencia en la filosofía de Kant.

Palabras Clave: percepción, finitud, transcendencia

\author{
JOSÉ M. GARCÍA GÓMEZ DEL VALLE \\ (Albert-Ludwigs-Universität Freiburg)
}

But ah, thought kills me that I am not thought.

\begin{abstract}
The aim of this paper is to provide an account of some decisive aspects of Kant's transcendental philosophy and its phenomenological interpretation by Heidegger. It focuses on "Kant's thesis on Being" with the purpose of locating the discussion in an explicitly ontological framework and outlining a certain understanding of the phenomena of Finitude and Transcendence within Kant's Philosophy.

Keywords: perception, finitude, transcendence
\end{abstract}

SHAKESPEARE, Sonnet 44

El presente escrito pretende trazar un posible recorrido en el interior del complejo doctrinal kantiano -y esto, además, atendiendo principalmente a la letra de Kant- que quizás sirva para dar cuenta de algunos aspectos decisivos de la filosofía transcendental kantiana y de su lectura fenomenológica por Heidegger. Se centra para ello en la denominada "tesis de Kant sobre el ser”. Esta elección viene determinada por el propósito de situar la exposición en un marco explícitamente ontológico y de esbozar cómo, desde el mismo desarrollo temático de la noción de ser, se abre camino en la filosofía de Kant una cierta comprensión de los fenómenos de finitud y transcendencia. 
En primer lugar, y para determinar el marco en el que quiere moverse la siguiente exposición, podría mostrarse en el propio corpus de textos kantiano los motivos por los que Heidegger puede afirmar que "filosofía transcendental no quiere decir otra cosa que ontología" (GA 24, p. 180) y, ello, además, en la convición de que “esta interpretación no es violencia alguna” (ibid.).

Como es sabido, la "tarea" de la "filosofía transcendental” toma la forma de la pregunta: “¿cómo son posibles los juicios sintéticos a priori?” (B 73) ${ }^{1}$ A partir de esta formulación es posible apreciar cómo Kant hace converger 'filosofía transcendental' y 'ontología', cuando, al definir 'ontología', la desliga de los márgenes disciplinares en los que ésta estaba inserta en la tradición de la filosofía escolar alemana del siglo XVIII y la hace encauzar con el proceder de su crítica de la razón:

\footnotetext{
Ontología es ciencia de las cosas en general, i.e. de la posibilidad a priori de nuestro conocimiento de las cosas, i.e. independientemente de la experiencia. Ella no puede enseñarnos nada acerca de las cosas en sí mismas, sino sólo de las condiciones a priori bajo las cuales podemos conocer en general cosas en la experiencia; i.e. principios de posibilidad de la experiencia (Refl. 5936; AA 18, p. 394).
}

Como muestra esta definición kantiana de ontología, la ciencia de lo ente en general, scientia entis in genere según la definición de Wolff (Ontologia, §1), la pregunta por lo ente en tanto que tal -òn hê ón, o de nuevo, en Wolff: ens... quatenus ens est (ibid.)-, se orienta en Kant a una investigación acerca de la constitución a priori del ‘conocimiento' y de la 'experiencia'. La determinación de en qué consista en general lo ente dependerá en último término de cómo se constituya el acceso a eso que es, i.e. la 'experiencia'. Si, como Kant afirma, el acceso a lo que es, a lo ente en general, la 'experiencia', se consuma en el 'conocimiento' y éste, a su vez, se determina como un 'juzgar', el 'conocimiento' de 'las cosas en general', en tanto que dadas en la experiencia, ha de producirse en lo que Kant denomina un 'juicio sintético'. Por otro lado, si la constitución de lo conocido en la experiencia es proyectado antes de la experiencia misma, en el sentido de que tal constitución se muestra condición de la experiencia en general y, por tal razón, como independiente de ella, ${ }^{2}$ la pregunta que ha de plantear la ontología debe concernir a las condiciones de posibilidad de los conocimientos o los juicios sintéticos a priori. Kant lo hace explícito de modo ejemplar en el siguiente pasaje de una de sus lecciones sobre metafísica: "La primera pregunta en la ontología, y la más importante, es: ¿cómo son posibles los conocimientos sintéticos a priori? Esta cuestión ha de ser resuelta en primer lugar; pues la ontología al completo se fundamenta en la resolución de esta pregunta”. (MP, p. 20)

Las caracterizaciones de la ontología que Kant ofrece ponen entonces en primer plano la cuestión del conocimiento. Y en este punto habría que dejar anotado lo siguiente: que esto sea así, que se hable aquí de ‘conocimiento’ y ‘juicio’, viene motivado por el planteamiento mismo de la pregunta por lo ente en tanto que tal y, en Kant, por el 'objeto', i.e. objeto de conocimiento y de experiencia. La pregunta por las condiciones de posibilidad del conocimiento, por su posibilidad a priori (su possibilitas), remitirá al cabo a la pregunta por la cognoscibilidad, por la objetividad del objeto de experiencia, del mismo modo en que por ejemplo la pregunta por lo

\footnotetext{
Kant se refiere también a esta pregunta como “la empresa más importante, si no la única” de la lógica transcendental (A 154/ B 193) y como “la auténtica tarea de la razón pura” (B 19).

2 El propio Kant remarca el sentido de ese 'antes', como algo distinto de una determinación 'intratemporal', cuando establece que: "Según el tiempo (o en el orden temporal) ningún conocimiento en nosotros antecede a la experiencia, y con ella comienza todo. Sin embargo, aunque todo nuestro conocimiento tenga lugar con la experiencia, no por ello se origina todo nuestro conocimiento a partir de (o desde) la experiencia." Es por eso que Kant se plantea la pregunta de "si hay un conocimiento independiente de la experiencia e incluso de todas las impresiones de los sentidos”, i.e. un conocimiento que pueda denominarse 'anterior' en aquel sentido no intratemporal, i.e. un conocimiento a priori. (B 1)
} 
ente (tí tò ón) terminaba por identificarse en Aristóteles a la pregunta por la 'esencia', 'entidad' o 'enticidad' (tís he ousía). ${ }^{3}$ En este desplazamiento, en el que Heidegger cifra el sentido del 'giro copernicano', se consuma, entonces, el proyecto kantiano de una ontología: "La Crítica conduce en su consumación a que el problema sufra una transformación: los juicios sintéticos que son en general posibles [sc. a priori], lo son sólo del ser y no de lo ente: como juicios ontológicos" (Kant-Seminar, p. 4). ${ }^{4}$

Según esto, la cuestión del conocimiento no convierte eo ipso a la filosofía de Kant en 'teoría del conocimiento’. De hecho, el que el conocimiento entre en juego en fundamental concordancia con el planteamiento ontológico, ni tan siquiera representa lo distintivo del esbozo kantiano de una ontología, pues antes que él v.g. Baumgarten definía la 'ontología' como "la ciencia de los predicados más generales de lo ente” (Metaphysica, §4), que a su vez no son sino "los primeros principios del conocimiento humano" (ibid., §5). ${ }^{5}$ No es entonces la pregunta por el conocimiento lo propio del proyecto kantiano de una ontología, sino que, más bien, se podría decir que este cuestionamiento es la forma característicamente moderna de la pregunta por el ser de lo ente (i.e. Kant se integra, más bien, en una tradición que desde la filosofía que a él le era inmediata se retrotrae, pasando v.g. por Wolff, hasta Descartes). ${ }^{6}$

Lo propio de Kant ha de cifrarse más precisamente en que la cuestión de 'la posibilidad $a$ priori de nuestro conocimiento de las cosas', en el mismo desplazamiento desde la pregunta por lo ente a la pregunta por el ser, hace valer una ruptura en el ámbito en el que se jugaba hasta entonces la validez del conocimiento, i.e. en el ámbito de la 'razón pura' entendida principalmente como mera armazón lógica. Esa ruptura la representa el reconocimiento de la necesidad de una estricta y fundamental donación del contenido de conocimiento y, con ello, la ruptura con cualquier pretensión de absoluto en relación con el conocimiento humano. El sujeto cognoscente humano no está desligado (absolvo) como razón pura o entendimiento en su mero uso lógico, sino que está siempre y en primer lugar referido a lo ente en tanto que éste ha de venir dado. Se trata, entonces, de la remisión última a la necesidad de la donación del objeto de experiencia, la cual toma expresión en Kant en denominaciones tales como la de 'intuición', 'sensibilidad' o 'receptividad', pero también en la caracterización del entendimiento no ya sólo como "facultad de pensar", sino más precisamente como "facultad de pensar el objeto de intuición sensible” (A 51/ B 75). Esa referencia a 'lo dado', i.e. a lo dado en la experiencia, encuentra diversas formulaciones en la obra de Kant, entre ellas la de la determinación del suelo sobre el que se gesta su $K r V$ como "el fértil bathos de la experiencia” (AA 4, p. 373, en nota). $\mathrm{Y}$ este planteamiento se traduce tanto en su determinación del concepto de lo transcendental (por la que "la palabra transcendental (...) no significa algo que excede toda experiencia, sino lo que la antecede (a priori), pero que, sin embargo, no está determinado para otra cosa que hacer posible el conocimiento de la experiencia”; ibid.), como en su noción de ontología, según la cual la "ontología es aquella ciencia (en tanto que parte de la metafísica) que constituye un

Vid. Met. VII, 1028 b 2 ss.

"La pregunta por la posibilidad del conocimiento óntico deviene así pregunta por la posibilidad del conocimiento sintético a priori, i.e. del ontológico” (GA 27, p. 256); por lo que, según Heidegger, "el resultado de la 'Crítica de la razón pura' justo hasta la dialéctica transcendental es: no hay conocimiento general a priori de lo ente, no hay conocimiento óntico-apriórico, sino sólo un conocimiento a priori en tanto que ontológico.” (ibid., p. 276)

5 De hecho, Kant criticó la conocida definición de la metafísica de Baumgarten como scientia primorum in humana cognitione principiorum (ibid., § 1) y esto, además, en relación con la delimitación de la metafísica frente a otras disciplinas (aquí explícitamente frente a la psicología empírica): "Nadie ha sabido nunca con certeza qué es la metafísica, por mucho que se haya tractado de ella durante tanto tiempo. Nadie supo determinar sus límites; y por ello se incluía en ella lo que no le pertenecía; lo cual, a su vez, dependía de la definición por la cual se la definía mediante 'los primeros principios del conocimiento humano'. Ahora bien, mediante esa definición aún no se ha determinado nada...” (MP, p. 129; vid. asimismo A 844/ B 871)

$6 \quad$ Cf., v.g., GA 41, p. 117. Sobre la vinculación de la pregunta ontológica con la pregunta acerca del conocimiento en el marco de la filosofía moderna desde Descartes, vid. Kant-Seminar, p. 2; GA 23, pp. 105 ss.; GA 36/37, pp. 37 ss.; o GA 41, pp. 68 ss. 
sistema de todos los conceptos y principios del entendimiento pero sólo en la medida en que éstos se dirigen a los objetos que pueden darse a los sentidos y hacerse patentes mediante experiencia” (AA 20, p. 260).

Es entonces la pregunta por la posibilidad a priori del conocimiento sintético, i.e. del conocimiento de experiencia, en la que se hace valer además la necesidad de la fundamental donación del objeto de experiencia, lo que distingue al esbozo de ontología kantiano del modo de proceder de la ontología tradicional (v.g. de la ontología racionalista de la filosofía escolar alemana). En lo distintivo de la formulación kantiana de esta pregunta radica igualmente su carácter propiamente 'crítico', aquél que acentúa la mencionada convergencia con el proyecto de una filosofía trascendental ${ }^{7}$ y que da cuenta fundamentalmente de aquella ruptura con toda pretensión de absoluto: el carácter necesariamente finito del conocimiento, que es, a su vez, el del sujeto cognoscente. La de Kant es por ello para Heidegger, aún en 1961, una "ontología crítica ligada a lo dado de la intuición sensible” (GA 9, p. 462).

\section{II}

Como ensayo de lectura bien diferenciado, por ejemplo frente a la exégesis de la denominada 'interpretación metafísica alemana' ${ }^{8}$, se consuma el giro más radical de Heidegger hacia una comprensión ontológica (o metafísica) de la filosofía kantiana en su obra de 1929 Kant und das Problem der Metaphysik (KPM), donde señala explícitamente una suerte de 'afinidad electiva' entre el proyecto kantiano de una ontología y la propia 'ontología fundamental' esbozada en Sein und Zeit (SZ). ${ }^{9}$ En estos parágrafos, Heidegger, partiendo de la pregunta histórica tí tò ón, en el sentido del òn hê ón, se propone mostrar cómo Kant asume y plantea tal pregunta en un recurso a la finitud del 'ser-ahí humano' (menschliches Dasein) y su transcendencia.

Para exponer brevemente esta vinculación de finitud y transcendencia en articulaciones estrictamente kantianas se podría recurrir por ej. a la argumentación de $K r V$ que apunta a cómo la idealidad del espacio y del tiempo es, por un lado, garante de la validez de nuestro conocimiento de los objetos de experiencia, al mismo tiempo que, por otro lado, clausura toda posibilidad de obtener un acceso a eso que las cosas sean 'en sí'. Del mismo modo, las categorías y los principios del entendimiento abren un ámbito de cognoscibilidad a priori, pero la condición para que éste pueda realizarse objetivamente (vid. 'objektive Realität') es que esas categorías y esos principios sean aplicables en última instancia sólo a objetos de experiencia. Es decir, la argumentación de Kant en $K r V$ apunta de alguna manera ya desde el principio a la íntima pertenencia y coimplicación de los fenómenos que Heidegger mienta con finitud y

\footnotetext{
Según las anotaciones de uno de sus cursos sobre metafísica, la ontología ha sido “tractada [...] sin crítica” - “¿qué era entonces la ontología? Una ontología que no era filosofía transcendental.” (AA 29, p. 784 s.) Igualmente, según el texto de Metaphysik Dohna, Kant declara haber expuesto la ontología hasta cierto punto sólo “dogmáticamente”, i.e. "sin atender a cómo se generan estas proposiciones a priori”. Y sigue: “Ahora queremos exponerla críticamente. De lo que aquí se trata es de: $1^{\circ}$ cómo se generan a priori los conceptos, $2^{\circ}$ cómo son posibles las proposiciones sintéticas que tenemos en ontología. De este modo queremos ahora tractar críticamente la ontología.” (AA 28, p. 650 s.) Por ello, en la "ontología elaborada o trabajada críticamente” de Kant, "todo depende de la pregunta: ¿cómo son posibles las proposiciones sintéticas a priori?” (AA 28, p. 703)

8 Sobre la contraposición de Heidegger con la interpretación de Kant orientada en la metafísica véase la nota al comienzo mismo de KPM en la que Heidegger expresa su principal objeción ante aquellas lecturas, i.e. "que se agarran a una concepción de la Crítica de la razón pura como ‘teoría del conocimiento’ y ahora entresacan también, a su lado, la metafísica y los 'motivos metafísicos'.” (Heidegger GA 3, p. 6, nota 4; cf. sobre esto GA 21, p. 117, GA 24, p. 216, nota, así como GA 25, pp. 66 s.) Heidegger llega a afirmar en una carta a Rickert del 25 de julio de 1929 que "mediante la inclusión externa de la metafísica, lo que sucede en Heimsoeth y otros, no sólo no se ha ganado nada, sino que ni siquiera se ha alcanzado la rigurosidad (o profundidad) de la anterior interpretación de Kant [isc. de los neokantianos!].” (Heidegger / Rickert, 2002, p. 62.)

$9 \quad$ Vid., sobre todo, GA 3 §§ 39, 40 у 45.
} 
transcendencia. Así, para que lo ente se nos dé en el conocimiento finito como aparición, el objeto de experiencia ha de venir de algún modo ya articulado y más concretamente, para Kant, el sujeto ha de 'predisponer' o de 'prefigurar' el modo de tal aparecer. Es a esta 'pre-figuración', que se hace problema sólo desde el presupuesto de que el sujeto cognoscente humano no tiene representativamente al objeto en tanto que 'cosa en sí', i.e. en tanto que el objeto ha de venir dado y no es creado ónticamente en el conocimiento mismo ${ }^{10}$, a lo que responde el tema kantiano de lo a priori. Y, a su vez, sólo porque tomamos el objeto como aparición y no como cosa en sí, i.e. sólo porque se asume la finitud del conocimiento, puede predicarse algo a priori de ese objeto de experiencia, de la aparición, con validez, etc.

Según esto, Heidegger puede llevar su lectura de Kant al terreno de la ontología fundamental, interpretando e.g. que la finitud del conocimiento, que "consiste en el recibir o aceptar de lo que se da (im Hinnehmen des Sichgebenden)” (GA 3, p. 147), se funda en última instancia en la "experiencia fundamental de la remisión a la donación (Grunderfahrung der Angewiesenheit auf Gebung)" (ibid., p. 297), y que es entonces el "estado de yecto (Geworfenheit)" el fundamento al que ha de retrotraerse la finitud del conocimiento, "como remisión al ente que no somos nosotros mismos.” (Ibid., p. 298; cf. GA 25, p. 85) Igualmente, para darse como ente, éste debe ser reconocido ya como tal, i.e. en vista de su "constitución de ser” (GA 3, p. 70). El sujeto finito ha de mantener abierto un 'espacio de juego', un 'horizonte' en el que lo ente pueda aparecer como tal, y "mantenerse de antemano en un espacio de juego semejante, configurarlo originariamente, no es otra cosa que la transcendencia que caracteriza todo comportamiento finito para con lo ente.” (Ibid., p. 71) Esta abertura del 'horizonte' o ‘espacio de juego' para la aparición, esta prefiguración del aparecer de lo ente como objeto de experiencia, viene posibilitada, en la interpretación heideggeriana de Kant, por la labor del 'esquematismo transcendental' que articula y vincula de igual manera sensibilidad y entendimiento y se identifica, por tanto, como aquella "raíz común, desconocida sin embargo para nosotros” (A 15/ B 29). ${ }^{11}$ Además, el esquematismo transcendental no sería sino el núcleo o fundamento de la articulación temporal del complejo cognoscitivo humano (o de su 'previa comprensión de ser'), lo que vincularía, en el marco mismo de la filosofía transcendental de Kant, los extremos del ser y del tiempo. Esto no sólo legitimaría a Heidegger a interpretar a Kant desde el ámbito de problemas puestos en cuestión en SZ, sino que igualmente explicaría

10 Cf. GA 3, p. 72. Vid., para esto, la famosa carta a M. Herz de febrero de 1772 en la que Kant expone la motivación de lo que será su filosofía transcendental, a saber: “¿sobre qué fundamento se sostiene la relación de aquello que llamamos representación en nosotros con los objetos?” (AA 10, p. 130; cf. GA 21, p. 115). Según el filósofo, si la relación de nuestra representación con el objeto "fuera activa" (AA 10, p. 130), i.e. si nuestra representación misma fuera “originaria” (origo), ónticamente creadora del objeto representado, no implicaría problema alguno comprender su "conformidad" (ibid.) con éste. Sin embargo, ni el entendimiento humano es arquetipo (sino ectipo), ni la intuición intelectual (sino sensible), y es desde esta premisa, y sólo desde ella, que las condiciones a priori de posibilidad de la experiencia se vuelven problema: desde el reconocimiento de la finitud del conocimiento humano como la "necesaria remisión a la receptividad (die notwendige Angewiesenheit auf Rezeptivität)" (GA 24, p. 213.).

11 Ante algunas de las formulaciones del propio Heidegger en este punto y ante la crítica a este aspecto de la interpretación heideggeriana de Kant por parte de e.g. D. Henrich (cf. Henrich, 1955), crítica asumida casi unánimemente en el ámbito de los estudios kantianos ( $c f$. Baum/Horstmann, 1979, pp. 68 s.) y que ha dado pie incluso a considerar el trabajo de lectura de KPM como “obsoleto” (Stolzenberg, 2001, p. 609), habría que recordar que, si bien es cierto que Heidegger remite críticamente la teoría de las facultades a una herencia cartesiana y como asunción dogmática (cf. e.g. GA 20, p. 248 y GA 21, pp. 282s.; vid. Dahlstrom, 1988, pp. 352 s. y 1991, pp. 344 ss.; Perego, 2001, pp. 54 ss.), en última instancia no postula la deducción o la génesis positiva de las facultades cognoscitivas 'sensibilidad' y 'entendimiento', a partir de una tercera facultad 'imaginación'. El que en las lecciones se explicite la necesidad de mantener la Eigenständigkeit de estética transcendental y lógica transcendental (cf. GA 25, p. 78) y se reconozca la Gleichursprünglichket de los complejos mentados por Kant con entendimiento y sensibilidad, espontaneidad y receptividad, etc. (cf. GA 25, p. 90 y GA 24, p. 212), invita a plantearse el sentido del giro en la interpretación de Heidegger hacia esa 'raíz común' o de la función de la imaginación transcendental y del tiempo, en otra clave que la propuesta v.g. por Henrich. Para esta cuestión, vid., sobre todo, Martínez Marzoa, 2004. 
que Heidegger haya visto la posibilidad de presentar una suerte de 'introducción histórica' a su opus magnum de la mano de una interpretación de Kant. ${ }^{12}$

\section{III}

Una manera (pues, ciertamente, hay muchas) de ahondar en el modo en que esas dos nociones, las de finitud y transcendencia, entran en una interpretación fenomenológica de $\mathrm{KrV}$ puede consistir en atender al complejo doctrinal kantiano que Heidegger refiere como 'la tesis de Kant sobre el ser'. ${ }^{13}$ El pasaje de $K r V$ que explicita esta 'tesis' reza: “Ser, obviamente, no es un predicado real, i.e. un concepto de algo que pudiera agregarse al concepto de una cosa. Es meramente la posición de una cosa o de ciertas determinaciones en sí mismas” (A 598/ B 626). ${ }^{14}$

'Ser' mienta para Kant, en principio, 'existencia' ('Dasein', 'Existenz'), en el sentido tradicional de existentia frente a essentia. ${ }^{15}$ Según la primera determinación negativa de 'ser', éste no es 'un predicado real'. Esto quiere decir que si 'ser' funciona en general como 'predicado', no podrá expresar una 'realidad' del sujeto gramatical al que se refiera en cada caso. 'Realidad’ (Realität), tal y como se conservó en la historia de la terminología filosófica hasta Kant, expresa principalmente lo propio de la res, lo que pertenece a una cosa. En este sentido, Kant puede identificar sin ambages 'realidad' con 'carácter de cosa' (o ‘cosalidad',

12 Cf. GA 3, "Vorwort zur 1. Aufl.” (1929), p. XVI; “Vorwort zur 4. Aufl.” (1973), pp. XIV s., y GA 67, p. 101. Es preciso señalar que tanto en este último texto (de 1938/39), como en una anotación manuscrita (de mitad de los años 30) que se reproduce en el prólogo a la $4^{\text {a }}$ edición de $K P M$, el propio Heidegger en cierta medida reprueba retrospectivamente la interpretación de Kant publicada en 1929 desde la nueva situación filosófica ganada tras el ‘fracaso' de SZ (Cf. Figal, 2000, pp. 21 s. y Grondin, 2003, p. 49). Según los mencionados apuntes de Heidegger, esta 'introducción histórica' representaba un "refugio” que, a su vez, "obstaculizaba el propio camino y lo hacía incomprensible (o 'malinterpretable’, mißdeutbar)” (GA 3, p. XIII), pues el ámbito (heredado, tradicional, etc.) desde el que se intentaba crear un acceso histórico a $S Z$, había sido "en verdad" abandonado definitivamente con esta obra (GA 67, p. 101). Sin embargo, hay que precisar que, aunque estas declaraciones reflejen el cambio de trayectoria del proyecto filosófico de Heidegger, según su propia interpretación, y su distanciamiento con respecto al planteamiento de SZ, eso no significa que la propia interpretación de Kant que se presenta en 1929 pierda su validez como tal interpretación: el ensayo de 1929 es (¡como introducción histórica a SZ!) “en sí equivocado, lo que no le quita un ápice de esencialidad a la interpretación de Kant (Dieser Versuch ist in sich irrig; was die Wesentlichkeit der Kantauslegung nicht antastet)." (GA 67, p. 101) Es más, si aquella "Einführung”, según Heidegger, se torna "Irreführung" (ibid.), esto no concierne a la propia interpretación de Kant que allí se lleva a cabo, sino que es el mismo proyecto de $S Z$, del que esta interpretación obtiene su Ansatz y su contexto, el que se ha vuelto fragwürdig, pues, como Heidegger afirma, si ésta es una "Irreführung”, lo será "aun cuando" o "incluso si" (Auch wenn) "en el ámbito del esquematismo pueden rastrearse ciertos ecos o resonancias (Anklänge) que indican a la relación del ser con el 'tiempo'.” (Ibid.)

13 Heidegger recurre a esta 'tesis' de Kant en los más diversos contextos y en trabajos escritos a lo largo de varias décadas. De hecho, las interpretaciones más completas las realiza en 1927, en las lecciones sobre 'los problemas fundamentales de la fenomenología' ( $c f$. GA 24, pp. 35 ss.; vid. Taminiaux, 1989), y en 1961, en su texto Kants These über das Sein (cf. GA 9, pp. 445 ss.; vid. Declève, 1970, pp. 230 ss., Klein, 1973 o Rebernik, 2006, pp. 221 ss.). Por razones obvias de espacio y de contexto no se discutirán las evidentes diferencias entre un tratamiento y otro de la 'tesis'. - Por otro lado, aquí tampoco se atenderá al enclave de la 'tesis' en la discusión acerca de la ‘argumento ontológico’ o de la “prueba cartesiana” o “anselmiana” (AA 28, p. 1243) de la ‘existencia de Dios’, i.e. en la crítica a los fundamentos de la teología racional de la dialéctica transcendental de $K r V$, pues puede entenderse que dicha crítica es más bien, en vista de su prosecución sistemática, la aplicación de la ontología de Kant, i.e. de la prima philosophia o metaphysica generalis entendida transcendentalmente, a una región de lo ente delimitada disciplinarmente en un ámbito de la metaphysica specialis. En cualquier caso, con esta delimitación se es fiel a la intención de Heidegger, quien afirma: “Aquí no nos interesa la cuestión de la demostración de Dios, sino el problema de la interpretación del ser.” (GA 24, p. 58; cf. también ibid., p. 56) Sobre la 'tesis’ de Kant en el contexto de su crítica a la 'ontoteología', $c f$. Henrich, 1960, pp. 137 ss.

14 Cf., igualmente, AA 28, p. 1027. Vid. Neumann, 2003 y Reisinger, 1992.

15 Sobre la contraposición explícita del uso kantiano frente a la fijación terminológica de esos conceptos por Heidegger, cf., v.g., GA 24, p. 36 y GA 31, p. 75. 
Sachheit) ${ }^{16}$ y afirmar simple y llanamente que "la existencia (Daseyn) no es una realidad" (AA 28, p. 313). Por otro lado, Kant define 'predicado real' como 'el concepto de algo que pudiera agregarse al concepto de una cosa'. Aquí se mienta un componente del concepto, un constitutivum, el cual, a su vez, no es sino una 'determinación' (determinatio, Bestimmung). ${ }^{17}$ A partir de estas declaraciones de Kant, aquí meramente enumeradas, que 'ser' no consista en general en un 'predicado real', significa que no mienta determinación, nota o componente alguno del concepto de una cosa. 'Ser' no expresa aquello que pertenece a la cosa o algo que la cosa pudiera tener (o que pudiera agregársele) como integrando el contenido de su concepto. Por lo dicho, 'ser' ni es en general 'algo', ni es reductible al concepto de algo, ni es, por lo tanto, reductible en general a concepto.

Pues bien, esto trae una serie de implicaciones para la interpretación de la filosofía de Kant, de las cuales se apuntarán ahora dos: en primer lugar, que se señale la irreductibilidad de 'ser' a concepto representa una clara ruptura de Kant con las determinaciones ontológicas básicas de la filosofía inmediatamente anterior. En palabras de Heidegger: "ser no será determinado ya desde el mero pensamiento.” (GA 41, p. 242). Esta podría ser, por tanto, una expresión de lo que Kant denominará su 'despertar del sueño dogmático', vinculado inextricablemente, a su vez, al reconocimiento del carácter finito a radice del conocimiento - algo que tal vez podrá apreciarse con cierta concreción en la exposición del aspecto ‘positivo' de la ‘tesis'.

Por otro lado, la segunda de las implicaciones que merece la pena destacar en este punto es especialmente relevante para situar el contexto, determinado por el planteamiento de $S Z$, en el que Heidegger acomete la interpretación de la 'tesis' kantiana sobre el ser, pues, como se sabe, él hace uso de la 'tesis' en sus lecciones de 1927 con la vista puesta en el 'problema fundamental' de la 'diferencia ontológica'. ${ }^{18}$ En esta lección llega a afirmar incluso: "la tesis de Kant, ser no es un predicado real, no se deja rebatir en su contenido negativo. Fundamentalmente, Kant quiere decir con ello: ser no es ente.” (GA 24, p. 77) Y en relación con esto quizás valga aquí el siguiente apunte: que Kant podría haberlo comprendido así, i.e. que 'ser' no es 'ente', o, expresado de otro modo: que no es una 'cosa' (Sache, Ding), lo da a entender una 'reflexión’ precrítica, según la cual los predicados son “conceptos mediante los cuales puedo conocer o poner ciertas cosas (Dinge). Según esto, todos los conceptos son predicados y significan: o bien cosas (Sachen), o bien su posición” (Refl. 4017, AA 17, p. 387). Pues bien, para Kant "lo primero es un predicado real..." (ibid. - cf. GA 24, p. 449). Por consiguiente, los predicados reales mientan, según la más inmediata literalidad de esta anotación de Kant, principalmente 'cosas' (Sachen). Si uno se toma en serio esta afirmación, se comprende por qué Heidegger intentaba en 1927 encontrar de la mano de la 'tesis de Kant sobre el ser' un rastro para el problema de la diferencia ontológica, y se concibe igualmente cómo podía aseverar aún en el año 1961 en relación con la 'tesis’ de Kant: “'Ser’ y 'es’ pertenecen con todas sus significaciones y variaciones a un ámbito propio. No son algo cosal (Dinghaftes), i.e. para Kant: no son algo objetual (Gegenständliches).” (GA 9, p. 452)

\section{IV}

'Ser', entonces, no significa 'predicado real’ o ‘determinación', no significa en general una 'cosa', sino ‘meramente la posición de una cosa'. Kant concibe dos posibles formas básicas de

16 Vid. por ej. A 143/B 182 y A 574/B 602. Cf. asimismo las aclaraciones de Heidegger en GA 3, pp. 86 s.; GA 9 , pp. 451 s.; GA 27, p. 255; GA 29/30, pp. 471 s.; o GA 41, pp. 215 ss. Sobre esto vid. Holzhey, 1981.

17 Praedicatum est vel constitutivum vel modale, prius determinatio (Refl. 5255; AA 18, p. 133). Vid. GA 24, p. 46: "Bestimmung, determinatio, meint das eine res Bestimmende, ein reales Prädikat."

18 Cf. GA 24, pp. 20 ss. (especialmente p. 23) y la nota marginal de Heidegger a Vom Wesen des Grundes, GA 9, p. 134, nota b. Vid. sobre esto Sallis, 1976 y von Herrmann, 1991. 
'posición': como posición relativa, la cópula, donde el predicado es puesto en relación con un sujeto en un juicio, y como posición absoluta, 'existencia'. En este segundo sentido se habla de 'ser' como de la 'mera posición de la cosa, o de ciertas determinaciones en sí mismas'. ${ }^{19}$ Aquí se trata, no ya de la posición respectiva de un predicado (de la conjunción de sujeto gramatical y predicado), sino de la "posición (Setzung) de la cosa con todos sus predicados” (MP, p. 40). La 'tesis', se ha dicho, representa en el complejo filosófico de Kant una posibilidad por la que la constatación del carácter finito del conocimiento, como necesaria remisión a lo dado, se abre camino desde la noción misma de 'ser'. Un posible indicio de esto vendría dado en que, como se mencionó, la comprensión de ser como posición, y fundamentalmente como posición absoluta, se hace cargo de la irreductibilidad de ser a 'concepto', o de cómo la determinación de 'ser' ha de ser ganada en un ámbito propio que no es el de lo conceptual (y, en general, el del pensamiento), pues según Kant “en el concepto de una cosa no puede encontrarse ningún carácter de su existencia” (A 225/ B 272).

Una primera indicación de este carácter irreductible de ser a concepto se encuentra en el hecho de que la proposición de existencia constituye un juicio sintético: "el ser en tanto que predicado sintético no es idéntico con el concepto de una cosa” (Refl. 5761; AA 18, p. 346 según la redacción de Erdmann). Sin embargo, esta primera indicación se topa con la siguiente dificultad, y es que, para Kant, tanto la determinación (i.e. el predicado real) como el juicio de posición absoluta (i.e. la predicación de existencia) son sintéticos. ${ }^{20}$ Es por eso que la afirmación del carácter sintético de ser como posición absoluta no da aún con lo distintivo de la proposición de existencia. La determinación, como "predicado que va más allá del concepto del sujeto y lo amplía” y que por ello "no debe estar ya contenido en él” (A 598/ B 626), aparece en juicios sintéticos, pues éstos son definidos en $K r V$ como aquellos "juicios extensivos (Erweiterungsurteile)” que "añaden un predicado al concepto del sujeto, el cual no podía haber sido pensado en él, y que no se podría haber entresacado mediante descomposición o análisis del mismo” (A 7/ B 11).

La diferencia entre 'existencia' (o 'ser' como posición absoluta) y 'determinación’ (o 'predicado real'), no puede residir entonces en la mera presencia de una síntesis, i.e. en el carácter sintético del juicio de 'existencia', sino más bien en el tipo distintivo de síntesis que se lleva a cabo en cada caso. Para comprender cómo Kant abre la posibilidad de que la predicación de existencia se lleve a cabo en una síntesis y que, al mismo tiempo, ésta no sea determinante o real, habrá que recurrir a la interpretación modal de la noción de 'ser' (i.e., en el sentido de 'efectividad', Wirklichkeit).

Que, como se ha mencionado, 'existencia' no sea 'una realidad' ( $c f$. AA 29, p. 313), se expresa v.g. en la configuración kantiana de la tabla de las categorías de $K r V$, en tanto que la categoría de 'realidad' tiene su asiento bajo el título o clase de la cualidad, mientras que la categoría de 'existencia' (o efectividad) es pensada bajo la modalidad. Por su parte, es bien sabido que a las categorías de modalidad (así como a los 'postulados del pensamiento empírico en general') se les adscribe en la filosofía transcendental un estatus especial, que se traduce en que “como determinación del obyecto (als Bestimmung des Objekts), no amplían en lo más

19 Con el giro de una “cosa”, o de una “determinación”, “en sí misma”, o más aun, de una "posición de la cosa en sí misma (Setzung des Dinges an sich selbst)" (AA 5, p. 401), no se hace mención a lo que en otro contexto se refiere como la 'cosa en sí' (en contraposición a la 'aparición'). Dicha diferenciación, aunque, como ya se ha dicho, es fundamental en el marco de la ontología transcendental crítica de Kant, no es en este momento temática ( $c f$. Heimsoeth, 1966 ss., vol. 3, p. 481, nota 120).

20 "Un juicio sobre la existencia de un obyecto (Existenz eines obiects) es siempre sintético” (Refl. 5767; AA 18, p. 348 - vid. también A 598/ B 626 y AA 20, p. 331). Aunque Kant también establece que "toda determinación es síntesis”, i.e. determinatio est praedicatum syntheticum (Refl. 5703 y 5701; AA 18, p. 330) Aquí, las expresiones 'síntesis' y 'sintético' se entienden en un sentido amplio, según la explicación que refiere cómo “en los juicios sintéticos debo salir del concepto dado para considerar, en relación con éste mismo, algo completamente distinto que lo pensado en él” (A 154/ B 193). 
mínimo el concepto al cual son añadidos como predicados” (A 219/ B 266). Es preciso plantear entonces en el contexto de las categorías de la modalidad (y los postulados, como principios modales del entendimiento) la cuestión de cómo puede afirmarse que la proposición de existencia posee carácter de proposición sintética y, aun así, no lleva a cabo adición real, de contenido, o determinación quiditativa. ${ }^{21} \mathrm{Si}$ el juicio sintético es necesariamente un juicio extensivo, de lo que se trata, entonces, es de comprender cómo en la proposición de existencia, según Kant, se consuma una suerte de extensión o de adición sin que ésta sea precisamente quiditativa, o lo que es lo mismo, de lo que se trata es de aclarar la naturaleza de esa síntesis particular del predicado modal.

Kant ofrece la siguente explicación en relación con los 'postulados':

Los principios de modalidad no son sintético-objetivos, porque los predicados de posibilidad, efectividad y necesidad no amplían en lo más mínimo el concepto del cual son dichos, de tal modo que añadieran aún algo a la representación del objeto. Ya que si bien son siempre sintéticos, lo son sólo subjetivamente, i.e. añaden al concepto de la cosa (lo real), del que aparte no dicen nada, la facultad cognoscitiva de la que surge y en la cual tiene su asiento. (A 233 s./ B 286 - nuestra cursiva)

En tanto que predicación modal, el juicio de existencia es siempre sintético, pero no sintético-objetivo, i.e. de contenido, real, sino sintético-subjetivo, y, además, subjetivo en el sentido bien determinado de que expresa la relación de la representación con el sujeto cognoscente, o mejor: con cada una de las diferentes facultades cognoscitivas del sujeto. ${ }^{22}$ Así, para Kant la adscripción de posibilidad, efectividad o necesidad no constituye predicado real alguno, pues esta predicación añade al sujeto gramatical sólo la referencia de la representación a cada una de las diferentes facultades cognoscitivas. En esta indicación de la referencia a la facultad cognoscitiva consistiría el tipo particular de ‘adición’ o ‘extensión’ del concepto de una cosa que consuman las categorías modales y por el que quedan legitimadas como predicados propiamente sintéticos. Hay que atender, por tanto, a cómo se concreta en Kant ese carácter ‘subjetivo-sintético’ de las categorías modales, y más específicamente, puesto que lo que interesa de la discusión modal es la determinación de ser como posición absoluta, atender a cómo concibe Kant desde su naturaleza modal lo propio de la efectividad, i.e. existencia, en su carácter distintivo (aquí ejemplarmente frente a posibilidad).

Interesa, entonces, seguir la exposición kantiana del tipo distintivo de síntesis subjetiva que se lleva a cabo en cada caso con la adscripción de posibilidad y de existencia. En 1763, Kant se plantea explícitamente esta cuestión y la formula del siguiente modo: “¿Puedo decir que hay (es) más en la existencia que en la mera posibilidad?” (AA 2, p. 75). Según Kant, para dar con una respuesta a este interrogante, se debería, en primer lugar, "distinguir entre qué es puesto y cómo es puesto.” (Ibid. - nuestra cursiva) Así, sigue Kant, “en relación con lo primero [sc. con el 'qué'], no es puesto más en una cosa efectiva que en una meramente posible, ya que todas las determinaciones y predicados de la cosa efectiva son encontrados en la mera posibilidad de la misma; sin embargo, en lo que se refiere a lo último [sc. al 'cómo'] sí que es puesto más mediante la efectividad.” (Ibid.)

Kant asume el problema, entonces, distinguiendo entre el 'qué' y el ‘cómo’ de la posición: el 'qué' que es puesto en la posibilidad, i.e. el concepto con sus determinaciones, es el 'qué'

\footnotetext{
Cf. sobre esto Bonevac, 1982, pp. 291 ss. y Reisinger, 1992, pp. 54 ss.
}

22 En ese sentido explica Heidegger en su curso sobre Kant del semestre de invierno de 1931/32, según la redacción del Nachschrift de Marcuse, que la “forma o categoría de modalidad asume un lugar particular entre las demás: no es un modo de la conjunción de sujeto y predicado, sino un modo de la posición de esta conjunción mediante el sujeto.” (Kant-Seminar, p. 12) - Heidegger debe de haber tenido presente en este punto, además de la 'aclaración' a los postulados ( $c f$. A 219/ B 266), aquel pasaje de $K r V$ en el que se lee que la "modalidad de los juicios" es "una función completamente particular de los mismos, que tiene en sí lo distintivo, de que no contribuye al contenido (...), sino que concierne exclusivamente al valor de la cópula en relación con el pensamiento en general” (A 74/ B 99 s.). 
puesto en la efectividad. El contenido o la constitución quiditativa del concepto de un posible y de un efectivo es, según Kant, idéntico. ${ }^{23}$ Aquí no se encuentra adición alguna al concepto, por lo que se aprecia igualmente, de nuevo, la diferencia entre 'existencia' (como predicado modal) y 'determinación’ (como predicado real). En la línea de lo mencionado acerca del carácter particular de las categorías modales, la posibilidad y la efectividad (existencia) son "tipos particulares de categorías que no contienen predicados de las cosas, sino sólo modos de poner los predicados de las cosas.” (MP, p. 41) Son, por tanto, ‘modales’ en sentido propio, en tanto que indican el 'modo', el ‘cómo' de la posición ${ }^{24}$, i.e. “no son predicados de las cosas en sí mismas, sino modi de cómo [sc. la cosa] es puesta (modi, wie es gesetzt wird)” (AA 29, p. 822).

\section{V}

Para Kant, lo decisivo para la aclaración de la existencia reside, en tanto que predicado modal, precisamente en el ‘modo', en el ‘cómo’ de la ‘posición’. Existencia y posibilidad, así, "difieren en el modo en cómo una cosa es puesta (in der Art wie ein Ding gesetzt wird)." (AA 29, p. 822) Kant asegura que el 'cómo' de uno y otro, i.e. el modo de posición, es distinto en cada caso ("die Art zu setzen ist verschieden”, MP, p. 40) y que esto que los distingue, en tanto que predicados 'sintético-subjetivos', no es sino "la relación para conmigo (die Relation zu mir)" (ibid.).

Esta relación, distintiva para posibilidad y para efectividad (ser, existencia), la define Kant con los siguientes términos: "si algo es sólo pensado, entonces es posible. Si algo es pensado porque ya está dado, entonces es efectivo.” (AA 28, p. 554 - nuestra cursiva). Esta definición de lo posible y lo efectivo atestigua en cierta medida lo dicho en relación con el carácter irreductible a concepto de la noción de ser: lo que distingue en principio a lo efectivo de lo meramente posible, es que aquél está de alguna manera dado (i.e. no es meramente pensado). En la posición específica de todo juicio de existencia, i.e. en relación con la adscripción de efectividad de lo representado, se recurre a esto dado que, a pesar de identificarse en su contenido real o quiditativo con lo meramente pensado, de algún modo, no queda cubierto sin resto por él. Lo puesto en el juicio de existencia es la cosa misma, en tanto que ésta comparece de por sí e inmediatamente en el conocimiento o la experiencia, en tanto que viene dada; y es en este sentido que en el caso de la predicación de existencia se consuma una suerte de ampliación o de añadidura (frente a lo que sucede en relación con la posibilidad).

Así, además, se reconoce como juicio sintético, en el sentido de que se lleva a cabo como un particular ‘salir del concepto' para considerar 'algo completamente distinto de lo pensado en él'. ${ }^{25}$ Ahora bien, por lo dicho, este ‘algo completamente distinto’ no es aquí determinación. Esto quiere decir que lo que aquí se considera no es una nota ${ }^{26}$ que convenga al concepto que sirve de sujeto gramatical y que pudiera añadírsele, ampliando así el contenido de aquel concepto. Aquí ese ‘algo distinto' de lo pensado en el concepto, no es en general otro concepto, no es al cabo algo conceptual. Es por eso que, como se ha mencionado, Kant no encuentra en el concepto de una cosa 'ningún carácter de su existencia' y por lo que puede afirmar que "a partir de meros conceptos no puede conocerse la existencia de una cosa” (Refl. 5758; AA 18, p. 87). Lo puesto en la posición absoluta, no es más que la cosa misma, en tanto que dada efectivamente al conocimiento.

\footnotetext{
Cf. GA 24, pp. 55 y 51.

Cf. GA 41, pp. 239 s.

Cf. la ya referida definición de ‘juicio sintético’ en A 154/ B 193.

Es sabido que en términos estrictamente lógicos 'nota' y 'concepto' (Merkmal y Begriff) son intercambiables, términos relativos distinguibles sólo contextualmente y cuyo uso depende únicamente de si lo que se mienta es una representación parcial (Teilvorstellung) o una "representación en sí misma” (AA 9, p. 58).
} 
Y, sin embargo, tanto lo posible como lo efectivo consuman una síntesis subjetiva, en la medida en que ambos añaden a la representación la específica vinculación de ésta con una u otra facultad cognoscitiva. Que lo dado implique, a diferencia de lo meramente pensado, una ulterior adición, significa una nueva vuelta de tuerca a la explicación de 'ser' como 'posición' en la que se consuma de un modo especialmente destacado aquella vindicación kantiana del carácter finito del comportamiento cognoscitivo humano para con lo ente.

Por lo dicho, la proposición de existencia ha de recurrir a 'lo dado' que se determina negativamente en principio como lo 'extra-conceptual' o lo 'no-conceptual'. ${ }^{27}$ En la medida en que la síntesis en la que se realiza la modalidad es 'subjetiva' en un sentido bien determinado, en el sentido de que refiere lo representado a cada una de las diferentes facultades del sujeto, lo 'dado', como lo carácterístico de la existencia, ha de tener igualmente una traducción posible en términos de 'actos' subjetivos, o más concretamente en Kant, tipos específicos de representación. En ese sentido, el complejo terminológico de la filosofía kantiana guarda para lo 'dado' denominaciones como las de 'sensación', 'afección', ‘impresión', 'intuición' o, fundamentalmente, ‘percepción’. Aquello que determina el ‘cómo’ de la posición, como en cada caso diferente si lo representado es puesto como posible o como efectivo, aquello que Kant refería como 'la relación para conmigo', se concreta entonces en el marco de $K r V$-como se indicaba ya a la hora de señalar el carácter sintético-subjetivo de la modalidad- como una "relación con la facultad cognoscitiva (das Verhältnis zum Erkenntnisvermögen)” (A 219/ B 266), de tal modo que la primera contraposición de lo posible y lo efectivo, en tanto que lo meramente pensado y lo dado, se expresa en que la 'posibilidad' mienta "la posición de la cosa en relación con el entendimiento", mientras que la 'efectividad' refiere "una conexión de la misma [sc. de la cosa] con la percepción.” (A 234/ B 287, nota).

La percepción cumple la función de una consumación fáctica y concreta de la objetualidad (determinada a priori y prefigurada por las formas puras de la intuición y del pensamiento) mediante un objeto que se nos da. Así, la percepción se determina como la denominación primordial para lo dado que permite adscribir efectividad a la cosa representada, de tal modo que para Kant la percepción no es sino “el único carácter de la efectividad” (A 225/ B 272 s.).

La posición absoluta revela la intrusión concreta del objeto de experiencia, de la cosa junto con sus determinaciones reales en una percepción, en tanto que efectuación (vid. Verwirklichung) de lo real mentado en la representación. ${ }^{28}$ El que la percepción traiga esta concreción a la representación del objeto lleva a Kant a describirla como "la materia de la intuición (Materie der Anschauung)”, como “intuición empírica en general” (A 180/ B 222 s.), pero también como aquello que proporciona el "material” (Stoff), "para pensar objetos de la intuición sensible” (A 375). ${ }^{29}$

A partir de lo expuesto, cabe recordar el ejemplo de Kant, con el que se exponía cómo “cien taleros efectivos no contienen más que cien posibles” (A 599/ B 627). La diferencia yace, entonces, para Kant en que con 'cien taleros efectivos' se mienta “el objeto y su posición en sí misma” (ibid.), mientras que con ‘cien taleros posibles’ se significa sólo “el concepto” (ibid.).

\footnotetext{
Cf. Janssen, 1987, p. 241.

28 En este sentido puede comprenderse igualmente el giro kantiano 'realidad objetiva', en el sentido de la realitas actualis, i.e. el concreto cumplimiento de un contenido quiditativo (de una 'realidad') ante el objeto o, más precisamente, según Heidegger, como aquella "cosalidad (Sachheit) que se cumple en el objeto en ella pensado, en su obyecto, i.e. aquella cosalidad que se constata ante lo ente experienciado como efectiva, como existiendo (als daseiend)” (GA 24, p. 49), i.e. como “aquel 'qué' que es efectuado” (ibid.).De igual modo puede entenderse por qué Kant afirma que "la existencia no es una realidad particular, si bien todo lo que existe debe tener realidad" (MP, p. 45).

29 Por otro lado, con ello la propia noción de ser cobra ciertos rasgos de contingencia, ya que una tal consumación de la objetividad del objeto se lleva a cabo sólo en tanto que el objeto mismo venga dado, y esto no podrá, al cabo, ser decidido a priori. Es por eso que según el texto de uno de los cursos de metafísica, Kant habría afirmado que "la existencia de una cosa no puede conocerse completamente a priori”, pues "aparte del pensamiento ha de añadirse aún algo, y esto es la intuición de algo efectivo, o la percepción” (MP, p. 41).
} 
Los cien taleros efectivos, podría decirse, están 'dados', son percibidos, mientras que los posibles son 'sólo representados', son sólo pensados. En este punto merece la pena traer a colación las aclaraciones de Heidegger acerca de la percepción y su carácter específico en tanto que comportamiento intencional. Heidegger formula esta cuestión con el siguiente ejemplo: “tengo la representación o sólo una representación de la pizarra (...), miento la pizarra misma, pero ahora en el modo del mero representar. Y surge la pregunta acerca de cuál es la diferencia de este mero-representar de la pizarra detrás de mí y el percibir de la pared frente a mí.” (GA 21, p. 101). No puede argumentarse, y aquí Kant y Heidegger han de coincidir, que el merorepresentar haya de ser más indeterminado frente al percibir, pues no son -en los términos empleados hasta ahora- las determinaciones reales, no es lo estrictamente quiditativo lo que diferencia a lo efectivo de lo posible o, aquí, a lo percibido de lo sólo representado: "la diferencia de grado, de contenido, no es una diferencia esencial que permita distinguir el representar del percibir”, i.e. no es algo que pudiera “diferenciar fenomenológicamente el representar y el percibir en referencia a su intencionalidad” (ibid. p. 102). Para Heidegger, esto podría decidirlo "únicamente el carácter de que, de manera determinada o indeterminada, en la percepción el ente mentado mismo está ahí ‘en persona’ (leibhaftig), mientras que en la representación, si bien es mentado, no está ‘en persona’ (leibhaftig).” (ibid.)

En vista del carácter intencional de la percepción, es posible, por tanto, precisar la noción kantiana de ser como posición, pues, para Kant, como se vio, la percepción no es sino 'el único carácter de la efectividad’. La percepción misma se muestra ahora -en confrontación con el mero representar- como un comportamiento intencional destacado, caracterizado por la Leibhaftigkeit, por mentar lo representado en la percepción como estando ahí 'en persona': “lo percibido en tanto que tal tiene el carácter de la Leibhaftigkeit, i.e. el ente que se presenta (sich präsentiert), tiene el carácter de lo ahí-'en persona' (Leibhaft-da)” (GA 20, p. 53). Así, la percepción, como "un caso destacado del cumplimiento intencional (intentionale Erfüllung)" (ibid., p. 59) caracterizado por la Leibhaftigkeit, valida la adscripción de existencia a lo mentado. ${ }^{30}$

30 Ahora bien, Heidegger plantea esta exposición del carácter distintivo de la percepción en el contexto de una confrontación con la figura filosófica de la fenomenología de Husserl y en un tono explícitamente crítico. Ya en las lecciones tempranas de Friburgo, de la mano de un análisis de la 'vivencia del mundo circundante' (cf. Gander, 2008, pp. 151 s. y 2009, pp. 149 ss.; de Lara, 2008, pp. 40 ss.), se destaca cómo el planteamiento de algo que ha de ser fijado como 'existente', retrotraído a meros datos de sensación, no delata más que lo que Heidegger denomina el 'primado de lo teórico' ( $c f$. GA 56/57, p. 85). Sólo así puede en general ser planteada en general la pregunta por la 'existencia' de la 'cosa', en tanto que lo ente es arrancado de su pertenencia a un mundo circundante significativo y es tenido ya sólo como mera cosa, como algo que "meramente está ahí como tal, i.e. que es real, que existe”, pues "realidad no es una caracterización mundano-circundante, sino una caracterización específicamente teórica, la cual yace en la esencia del carácter de lo que es al modo de una cosa (Dinghaftigkeit)”. (Ibid., p. 89 - atiéndase a que aquí Heidegger utiliza 'realidad' [Realität] indistintamente para referirse a efectividad, en el sentido e.g. del giro 'realidad del mundo externo’ [Realität der Außenwelt]; cf., sobre todo, ibid., p. 91.) Esta problematización de la noción misma de 'cosa de percepción' en tanto que tenida para la contemplación teórica como meramente ahí 'existente', se hace explícita de nuevo en el contexto de las lecciones de Marburgo a las que se pudo recurrir para dar con la caracterización de la percepción desde la Leibhaftigkeit (vid. sobre esto, Volpi, 1984, pp. 165 ss., Taminiaux, 1989, pp. 89 ss.) En este sentido, Heidegger explica: "La Leibhaftigkeit es un carácter de confrontación (Begegnischarakter) de las cosas mundanas (Weltdinge), en tanto que el mundo se confronta meramente en un puro aprehender (Vernehmen), en un puro percibir (Wahrnehmen).” (GA 20, p. 265) Así: “el modo de confrontación de la cosa natural en el carácter de la Leibhaftigkeit, de la característica intensidad (Aufdringlichkeit) de la cosa natural, que muestran las cosas mundanas en tanto que son meramente percibidas, este carácter de la Leibhaftigkeit tiene su suelo en una específica des-mundanización del mundo circundante (spezifische Entweltlichung der Umwelt). La naturaleza, como obyecto de la ciencia natural, es en general descubierta únicamente en una tal desmundanización.” (Ibid., p. 266). En lo que se refiere al proyecto filosófico de Kant, esto quiere decir que su mismo planteamiento se mueve ya en el marco de 'lo teórico', en el que aquello cuya 'existencia' se pone en cuestión es comprendido ya como 'cosa natural', como vorhanden. Según esto, Kant, “como la tradición antes y después que él, de antemano ha pasado ya por alto aquel ámbito de las cosas en el que nos sabemos inmediatamente familiarizados.” (GA 41, p. 214) 
Aun cuando lo expuesto hasta ahora en relación con lo dado y la percepción pueda levantar la sospecha de no haber hecho más que redundar en una "expresión metafórica que nada dice" (Schopenhauer, 2000, p. 51) y más importante, incluso si lo referido hasta ahora, como mero trazo de un posible camino a través del complejo doctrinal kantiano, está lejos de haber traído a cumplimiento (precisamente en el sentido fenomenológico de Erfüllung) lo mentado en él, i.e. los problemas a los que responden y en los que alcanzan concreción las denominaciones empleadas anteriormente y esos términos y desarrollos kantianos, es preciso, para seguir con el registro de los rasgos de la filosofía kantiana que aquí interesan, así como de su interpretación por Heidegger, atender ahora a algunas derivas especialmente problemáticas de la vinculación de la percepción con la existencia en la obra de Kant.

Pues, para Kant, percepción no sólo es criterio o "único carácter" de la existencia (efectividad), sino también "representación de lo efectivo (Repräsentation des Wirklichen)" (MP, p. 45) e incluso "lo efectivo mismo" (A 375). Tras lo expuesto en relación con el aspecto negativo de la 'tesis' ('ser' no es ‘ente') resulta especialmente difícil admitir como legítimo este desplazamiento, pues no se comprende cómo aquello que hace a la efectividad (y, aquí, al ser en tanto que posición absoluta) puede ser ello mismo algo efectivo y en última instancia, por tanto, ente o cosa. ${ }^{31}$

La ambigüedad de los términos intencionales en la obra de Kant es bien conocida: 'representación', 'intuición', etc., en última instancia intentio, significa en Kant de un modo indiferenciado tanto el intendere como el intentum. ${ }^{32}$ Así, por ej., 'representación' mienta tanto el 'representar' como lo 'representado', tanto el 'acto' de representarse algo, como el ‘contenido’ de la representación o aquello que (en el acto de representar) es representado. Evidentemente, 'percepción’ cae víctima de la misma ambigüedad, significando tanto el percibir, como lo percibido. De hecho, en la discusión de la noción de ser como posición absoluta, esta ambigüedad es solidaria de aquella que para Heidegger deja sin determinar la noción de 'perceptibilidad' (Wahrgenommenheit), como aclaración kantiana del carácter de ser o existencia, en tanto que 'posicionalidad' (Gesetztheit). ${ }^{33}$

Otra deriva problemática de la vinculación en la obra de Kant de percepción con existencia parece a primera vista minar incluso su mismo planteamiento, y sin embargo, como se verá, será apropiado en la interpretación de Heidegger de modo especialmente productivo. Así, en la exposición kantiana de la percepción, ésta viene definida como "representación acompañada de sensación” (KrV B 147). Aun admitiendo la ambigüedad connatural al uso kantiano de los términos intencionales, 'percepción’ da cuenta de la donación de la cosa de modo inmediato, concreto o empírico: "Lo empírico (...), i.e. aquello mediante lo cual un objeto es representado como dado según su existencia, se denomina sensación (sensatio, impressio), la cual hace a la materia de la experiencia y, vinculada con consciencia, se denomina percepción.” (AA 20, p. 276). Percepción refiere, entonces, la efectuación o cumplimiento de una realidad mediante un objeto (junto con lo real de sus posibles determinaciones predicables) que desde sí se impone o irrumpe, y que en tanto que comparece, como ahí 'en persona', valida la adscripción o predicación de su existencia. En la percepción, lo mentado como ahí ‘en persona’ es el objeto

31 Kant escribe: “las cosas sólo son dadas (...) en la medida en que son percepciones” (B 147 - nuestra cursiva), de lo que se podría entresacar que, efectivamente, se produce en Kant una suerte de desplazamiento de la 'percepción' hacia la 'cosa', y -por lo dicho- del carácter de ser (o de 'existencia') hacia lo ente (o lo 'existente'). Para este pasaje, sin embargo, habría que atender a cómo el uso del plural en estos casos denota explícitamente en Kant un 'significado material'; $c f$. sobre esto el apunte de Kant 'sobre el significado formal y material de algunas palabras', Refl. 5663, AA 18, p. 322.

32 Cf. v.g. GA 3, p. 50; GA 24, p. 64; o GA 25, pp. 84 y 110. Vid. en general sobre esto Knüfer, 1911, pp. 74 s.

33 Cf. por ej. GA 24, p. 66. 
existente como empírica y materialmente ${ }^{34}$ dado mediante sensación. Sin embargo, y esto es decisivo en la discusión de la noción de ser desde la percepción y de la implicación en ésta de la sensación, según Kant, la propia sensación "presupone la efectiva presencia del objeto (die wirkliche Gegenwart des Gegenstandes voraussetzt)" (A 50/ B 74). ${ }^{35}$

De hecho, la vinculación de la sensación con la 'presencia' (Gegenwart, praesentia) del objeto es referida por Kant casi desde los comienzos de su actividad filosófica. ${ }^{36}$ De esta suerte, v.g. en la década de los 50, sin reconocer aún para sensación (o intuición) un carácter de representación específica (frente a concepto), podía definir la sensación como “el concepto de las cosas presentes", ya que "sentimos sólo lo que está presente (wir empfinden nur, was gegenwärtig ist).” (Refl. 2843 y 2844, AA 16, pp. 541 y 543, respectivamente). En la Dissertatio de 1770, donde ya aparece como ganada la diferencia entre dos especies de representación, sensible e intelectual, es expuesta igualmente la referida determinación de la sensación (sensatio), según la cual, ésta consiste en la materia de la representación sensible (sensualis representationes materia), la cual delata (arguit) "la presencia de algo sensible (praesentiam quidem sensibilis alicuius)" (AA 2, p. 393). En este sentido, dice Kant: "todo lo que es sensible en el conocimiento depende de una índole especial del sujeto, en la medida en que es capaz de estas o aquellas modificaciones por la presencia del objeto (a praesentia obiectorum)" (ibid., p. 392).

Heidegger resume los pasos de lo expuesto hasta ahora del siguiente modo: "El carácter decisivo de la efectividad es percepción, el de la percepción: sensación, el de la sensación: afección, i.e. presencia, asistencia inmediata del objeto (d. h. Gegenwart, unmittelbare Anwesenheit des Gegenstandes).” (Kant Seminar, p. 12)

La sensación, entonces, presupone la presencia del objeto. La afirmación de Kant indica, por tanto, que la percepción, el 'único carácter de la efectividad', está remitida a la presencia. O lo que es lo mismo, se declara, en términos que destacan lo paradójico y problemático de esta deriva de la tematización de Kant, que lo puesto en la posición absoluta ha de haber sido, de algún modo, puesto de antemano (vid. voraus-setzen), y que sólo a partir de esta presuposición o previa posición puede llevarse a cabo la posición.

Si en la percepción es posible dar cuenta de la cosa mentada como ahí 'en persona', en el cumplimiento de su realidad, etc., es entonces porque percibir es descubrir lo ente como previamente siendo (praesens, presente). 'Percepción', según esto, no es 'ser', no es 'existencia', sino que señala más bien el modo del acceso a lo que de alguna manera ya ‘es’ o ‘existe’. Percepción quiere decir entonces en la interpretación heideggeriana de la 'tesis’ el “cómo de la aprehensión de algo puesto (Wie der Erfaßtheit eines Gesetzten)” o un "carácter de aprehensión de lo ente (Erfassungscharakter des Seienden)” (GA 24, p. 66 y 159).

Y lejos de quedar invalidado el camino esbozado por Kant desde la tematización de la noción de ser de la mano de la exposición de la percepción, como existencia o posición absoluta, es más bien en este punto en el que se consuma la interpretación de la 'tesis' que Heidegger desarrolla en 1927. En pocas palabras, de lo que se trataría es de que la percepción, interpretada

34 Obviamente, aquí ‘material’ no implica que pueda o deba ser constatado ‘físicamente', sino que refiere la ‘afección’ como modo específico de tener representativamente el objeto, como lo 'subjetivo' de la intuición, su carácter empírico, i.e. su 'materia' o ‘material' (Materie, Stoff).

35 "Sensaciones son, según Kant, las representaciones (los modos del tener de los objetos), 'que son efectuados mediante la presencia de una cosa'. Nosotros interpretamos, al contrario: en el sentir (Empfinden) la sensibilidad, la intuición está abierta para la presencia de las cosas.” (GA 21, pp. 116 s.; cf. Refl. 619; AA 15, p. 268)

36 Y esto, además, en directa conexión con su contexto teórico inmediato, lo que se aprecia v.g. atendiendo al texto de G. F. Meier Auszug aus der Vernunftlehre, que Kant utilizaba como manual o compendio para sus cursos de lógica (vid. Hinske, 1998, pp. 33 ss.). Aquí Meier, al identificar toda representación con concepto, y con ello también a la sensación (cf. Auszug, §§ 249 y 255; vid. igualmente Knüfer, 1911, p. 24), establecía que mediante 'sensación', i.e. "mediante experiencia inmediata sólo podemos alcanzar conceptos de cosas efectivas en la medida en que éstas nos sean presentes (Durch die unmittelbare Erfahrung können wir nur Begriffe von würklichen Dingen, in so ferne sie uns gegenwärtig sind, erlangen).” (Auszug, § 256)

Studia Heideggeriana, Vol. I, 2020, $2^{\text {a }}$ ed. 
como 'perceptibilidad’ (Wahrgenommenheit) o carácter de existencia, más que 'existencia' propiamente, lo que designa es un "modo de acceso a lo existente (Zugangsart zum Existierenden)” (ibid., p. 66), i.e. refiere, más bien, el carácter de estar descubierto en general (“Entdecktheit überhaupt”; ibid., 99) ${ }^{37}$, el cual, a su vez, se sostiene sobre el carácter de abierto del ser (Erschlossenheit), y más específicamente, en el modo de ser de lo contemplado como meramente presente o subsistente (Vorhandensein). Esto quiere decir que, para que algo pueda aparecer como 'presente' (vorhanden), i.e. para que algo pueda ser susceptible de ser descubierto (entdeckt), debe haberse comprendido ya de alguna manera 'ser' (y más precisamente en el sentido de Vorhandensein). "A la intencionalidad de la percepción”, concluye Heidegger, "no sólo pertenecen intentio e intentum, sino más aún la comprensión del modo de ser de lo intendido en el intentum (das Verständnis der Seinsart des im intentum Intendierten)." (Ibid., pp. 100 s.) Y es, en definitiva, porque en el tratamiento kantiano de la noción de ser como posición entra (si bien no de manera explícita o literal) la comprensión de que el carácter de abierto del ‘ser-presente’ está de algún modo ya presupuesto en el carácter de descubierto de lo ente, por lo que Heidegger cree poder dar con un indicación del problema fenomenológico fundamental de la diferencia ontológica de mano de la 'tesis' de Kant sobre el ser.

En último término, para Heidegger, "esta comprensión de ser es obviamente a lo que Kant recurre, aun sin verlo con distinción, cuando dice: existencia, efectividad es igual a percepción.” (ibid., p. 101)

\section{VII}

A partir de la exposición de la 'tesis' de Kant sobre el ser se ha atendido a cómo la posición absoluta o existencia, en vista de su carácter específicamente modal, era capaz de realizar una adición o extensión del sujeto gramatical, conformando así la proposición de existencia un juicio sintético. En tanto que modal, este juicio era además 'sintético-subjetivo', en el sentido de que la representación venía vinculada a cada una de las facultades cognoscitivas, determinando así el cómo de la posición en cada caso en la medida en que la cosa, junto con todas sus determinaciones reales, era puesta o bien como meramente pensada para el entendimiento o bien como dada para la intuición. Así se determinaba el modo específico de la posición, en la medida en que en cada caso se tratara de un posible o de un efectivo (existente). Lo 'posible' venía referido al entendimiento como meramente pensable. Lo 'efectivo', sin embargo, traía a la discusión la imposibilidad de reducir en general lo existente a pensamiento, a concepto. La existencia de una cosa se constata en tanto que la cosa misma comparece o se da; y es la percepción, como representación o consciencia del objeto vinculada a sensación, lo que da cuenta de la efectiva comparecencia de la cosa, del objeto, como ahí ‘en persona’. ${ }^{38}$ Este carácter

37 Heidegger explicita en este punto que el 'carácter de lo descubierto' (Entdecktheit) no ha de identificarse con el 'carácter de lo que es como meramente presente o subsistente, o lo que simplemente está ahí delante' (Vorhandenheit), i.e., aquí, con la ‘existencia de lo existente’ (die Existenz des Existierenden); cf. GA 24, p. 66.

38 Es cierto que la percepción no agota la determinación kantiana de la existencia y que Kant es explícito al señalar la necesidad de integrar las percepciones del objeto según leyes empíricas (cf. v.g. A 226/ B 273 s.), es más, que, como se nos ha recordado en la evaluación de este artículo, la donación misma del objeto implica 'vincular su representación a una experiencia’ ( $c f$. A 156 s./ B 195). Dar cuenta de la necesaria vinculación de lo dado y de la percepción del objeto en una experiencia, significaría de hecho adentrarse en la respuesta a la pregunta directriz de la ontología transcendental crítica de Kant (¿cómo son en general posibles a priori los juicios sintéticos?) en un grado que excede los límites de este escrito. Éste se detiene, por decirlo así, en un momento previo del planteamiento mismo de dicha pregunta: el de la necesidad de vincular la donación del objeto para el conocimiento con un a priori de la receptividad, el de la integración de la finitud del conocimiento en la prefiguración del objeto de experiencia como aparición, y, al cabo, el de la vinculación de los fenómenos que Heidegger refiere como finitud y transcendencia en el marco mismo de la filosofía transcendental kantiana. 
sintético-subjetivo de la existencia, como categoría modal, como dando cuenta de la posición de la cosa misma, marcaba la necesidad de algo no conceptual, de que aquello 'completamente distinto de lo pensado en el concepto de la cosa', que se añadía a la representación y que legitimaba a la proposición de existencia como sintética, no fuera ello mismo concepto. De acuerdo con este desarrollo, en Kritik der praktischen Vernunft (y, además, en un contexto de discusión crítico con la 'ontoteología', que es igualmente el de la 'tesis'), escribe Kant:

Conocer completamente la existencia (...) a partir de meros conceptos es absolutamente imposible, porque toda proposición de existencia, i.e. que dice de algo de lo que yo me hago un concepto, que existe, es una proposición sintética, i.e. una proposición mediante la cual yo voy más allá de aquel concepto y digo de él más de lo que en ese concepto es pensado: a saber, a este concepto en el entendimiento aún le es puesto correspondientemente un objeto fuera del entendimiento. (AA 5, p. 139)

Aquí se expresa la necesidad de lo 'dado', de lo que ha de corresponderse con el concepto (pero en tanto que 'dado' 'fuera de él'). Esto ‘dado', y que ha de corresponder al concepto, se refiere en la percepción, que no es más que el cumplimiento por el objeto mismo en tanto que dado (como ahí ‘en persona’), i.e. la efectuación empírica mediante sensación de lo que en el marco terminológico kantiano, como contrapuesto a concepto, se denomina intuición. La intuición aparece de modo destacado como aquel momento estructural del conocimiento no conceptual e irreductible a concepto. El necesario y constitutivo carácter de eso dado, el momento de la donación, y con ello igualmente la irreductibilidad de ambos momentos (de entendimiento y sensibilidad, de concepto e intuición) es enfatizado explícitamente por Kant en el marco de la exposición de la noción de ser en el contexto modal, llegando a afirmar que sin esa mencionada irreductibilidad, no podría en general haber diferencia entre lo efectivo y lo posible:

\footnotetext{
Al entendimiento humano le es necesario, de un modo indispensable, diferenciar entre la posibilidad y la efectividad de las cosas. El fundamento para ello yace en el sujeto y en la naturaleza de sus facultades cognoscitivas. Ya que si no fueran requeridos para su ejercicio dos elementos completamente heterogéneos, entendimiento para los conceptos e intuición sensible para los obyectos que les corresponden: entonces no habría tal diferencia (entre lo posible y lo efectivo). [...] Así, toda nuestra diferencia entre lo meramente posible y lo efectivo se basa en que lo primero significa sólo la posición de la representación de una cosa con relación a nuestro concepto y en general a la facultad de pensar, y lo último significa la posición de la cosa en sí misma (fuera de este concepto). (AA 5, p. 401)
}

Desde la misma tematización de la noción de ser, i.e. desde un desarrollo que toma pie en la tematización de un complejo doctrinal inserto paradigmáticamente en el problema de la ontología, se da con la fijación por parte de Kant del carácter irreductible de los dos momentos constitutivos de conocimiento y experiencia, el momento de la receptividad y de la espontaneidad, que se traduce en términos de especies de representación como intuición y concepto, y que por ser susceptibles de ser traducidas igualmente al lenguaje de las facultades cognoscitivas como entendimiento y sensibilidad, da cuenta de una duplicidad irreductible en el propio sujeto cognoscente humano y en su comportamiento para con lo ente.

La irreductibilidad de 'ser' a 'pensamiento' se refería como la necesaria remisión a lo no conceptual, y a esto último se lo denominó formalmente lo ‘dado'. Esta remisión a lo dado, constitutiva de la noción misma de ser, señala no otra cosa que el carácter a radice finito del conocimiento. Y aquí, como se ve en el decurso mismo de la interpretación de Heidegger, desde esta constatación de la finitud, que en Kant es finitud tanto del conocimiento, como del sujeto cognoscente, se vincula necesariamente finitud y transcendencia (el previo comprender del ser de lo ente). 
En Kant, más concretamente, el momento de la finitud, de la necesaria remisión a la donación de lo ente, pasa a integrar, como receptividad o forma pura de la sensibilidad, lo a priori sobre lo que se efectúa la concreta comparecencia de lo ente. La percepción, así, como caso destacado de cumplimiento intencional, en la exposición de Heidegger, como constatación de lo ente efectivo en tanto que la cosa misma es puesta como ahí 'en persona', es cumplimiento también de lo a priori de la intuición; es asimismo 'cumplimiento de lo posible' ${ }^{39}$ por utilizar la formulación de Wolff, pues lo posible ahora, a diferencia de lo que sucedía en la metafísica escolar alemana, ya no se comprende sólo desde la pensabilidad y la no-contradicción ${ }^{40}$, sino que es lo 'posible real', ${ }^{41}$ lo que conviene "con las condiciones formales de la experiencia” (A 218/ B 266).

Lo propiamente transcendental de la filosofía kantiana hace que, en aquello que conforma previamente el acceso a lo ente, venga integrada y se haga vinculante y constitutiva la receptividad (i.e. la propia finitud) como "forma de la intuición (como una complexión subjetiva de la sensibilidad)”, la cual “antecede a toda materia (de las sensaciones)” (A 267/ B 323). Si la intuición sensible humana, en tanto que índice de la finitud como necesaria remisión a la donación de lo ente, deviene percepción 'en persona' (vid. leibhaftige Wahrnehmung) en su consumación concreta mediante sensación, i.e. en tanto que 'depende', como se vio, de la existencia del objeto y presupone la presencia (Gegenwart, praesentia) misma de la cosa, la filosofía kantiana vincula el momento de la finitud con el de lo a priori, i.e. vincula una cierta comprensión de aquello que Heidegger refería con finitud y transcendencia, de tal modo que la consumación concreta de lo intendido en la intuición y dado ahí 'en persona' es posible, más bien, a partir de la previa conformación o prefiguración de esa presencia por parte de la sensibilidad pura, de manera que aquella consumación o aquel cumplimiento presupone ontológicamente estas formas a priori de la sensibilidad. ${ }^{42}$

Con el despliegue de la 'tesis' de Kant sobre el ser se aprecia, en un contexto explícitamente ontológico, el modo en que la constatación de la finitud del conocimiento, no sólo se abre paso en la tematización de la noción misma de ser, sino que se integra en la comprensión de lo a priori, de modo que ese momento estructural a priori del acceso cognoscitivo a lo dado, la receptividad, deviene prefiguración y condición de posibilidad de la presencia misma.

\section{Referencias}

BAUM, M. y HORSTMANN, R.P. (1979), "Metaphysik und Erfahrung in Kants theoretischer Philosophie”, Philosophische Rundschau, vol. 26; pp. 62-91.

BAUMGARTEN, Alexander Gottlieb, Metaphysica, Halle/Magdeburg 1757, 3. Aufl. (Citado como Metaphysica)

BONEVAC, Daniel (1982), "Kant on Existence and Modality”, Archiv für Geschichte der Philosophie, vol. 69; pp. 289-300.

\footnotetext{
“Erfüllung des Möglichen”, cf. Wolff, Deutsche Metaphysik §14.

Cf. Wolff, Ontologia §85 y Deutsche Metaphysik §12. Vid., sobre esto, GA 23, p. 195.

Cf. v.g. A 596/ B 624, en nota.

En la relación de percepción e intuición, Kant lo formula del siguiente modo: "podemos conocer la forma de la intuición a priori, i.e. antes de toda percepción efectiva" (KrV A 42/ B 60 - nuestra cursiva). Con esto a la vista y reteniendo la anteriormente referida vinculación de percepción y efectividad (existencia, ser como posición absoluta, presencia), son las formas a priori de la sensibilidad, por ello, "condiciones de la existencia de las cosas en tanto que apariciones (Bedingungen der Existenz der Dinge als Erscheinungen)" (KrV B XXV - nuestra cursiva).
} 
DAHLSTROM, Daniel (1991), “Heidegger's Kantian Turn: Notes to his Commentary on the Kritik der reinen Vernunft”, Review of Metaphysics, vol. 45; pp. 329-361.

DAHLSTROM, Daniel (1988), “Heideggers Kant-Kommentar 1925-1936”, Philosophisches Jahrbuch; vol. 96.

DECLÈVE, Henri (1970), Heidegger et Kant (Phaenomenologica, vol. 40), The Hague.

FIGAL, Günther (2000), Martin Heidegger. Phänomenologie der Freiheit, Weinheim, 3. Aufl.

GANDER, Hans-Helmuth. (2009), "Phänomenologie der Lebenswelt: Husserl und Heidegger”, en: G. Figal / H.-H. Gander (eds.), Heidegger und Husserl. Neue Perspektiven (Heidegger Forum, Bd. 2), Frankfurt/M.; pp. 137-158.

GANDER, Hans-Herlmuth (2008), "La fenomenología hermenéutica del vivir fáctico de Heidegger”, trad. F. de Lara, en: F. Duque (ed.), Heidegger. Sendas que vienen, Madrid; vol. I, pp. 139-171.

GRONDIN, Jean (2003), "Der deutsche Idealismus und Heideggers Verschärfung des Problems der Metaphysik nach Sein und Zeit”, en: H. Seubert (ed.), Heideggers Zwiegespräch mit dem deutschen Idealismus (Collegium Hermeneuticum, Bd. 7), Köln/Weimar/Wien; pp. 41-57.

HEIDEGGER, Martin (GA 3) Kant und das Problem der Metaphysik, ed. F.-W. von Herrmann, Frankfurt/M. 1991.

HEIDEGGER, Martin (GA 9) Wegmarken, ed. F.-W. von Herrmann, Frankfurt/M 1996, 3ª ed.

HEIDEGGER, Martin (GA 20) Prolegomena zur Geschichte des Zeitsbegriffs, ed. P. Jaeger, Frankfurt/M. 1979.

HEIDEGGER, Martin (GA 21) Logik. Die Frage nach der Wahrheit, ed. W. Biemel, Frankfurt/M. 1995, $2^{\mathrm{a}}$ ed.

HEIDEGGER, Martin (GA 23) Geschichte der Philosophie von Thomas von Aquin bis Kant, ed. H. Vetter, Frankfurt/M. 2006.

HEIDEGGER, Martin (GA 24) Die Grundprobleme der Phänomenologie, ed. F.-W. von Herrmann, Frankfurt/M. 1975.

HEIDEGGER, Martin (GA 25) Phänomenologische Interpretation von Kants Kritik der reinen Vernunft, ed. I. Görland, Frankfurt/M. 1977.

HEIDEGGER, Martin (GA 27) Einleitung in die Philosophie, ed. O. Saame/I. Saame-Speidel, Frankfurt/M. 1996.

HEIDEGGER, Martin (GA 31) Vom Wesen der menschlichen Freiheit. Einleitung in die Philosophie, ed. H. Tietjen, Frankfurt/M. 1982.

HEIDEGGER, Martin (GA 36/37) Die Grundfrage der Philosophie (1933), en: Sein und Wahrheit, ed. Tietjen, Frankfurt/M. 2001.

HEIDEGGER, Martin (GA 41) Die Frage nach dem Ding. Zu Kants Lehre von den transzendentalen Grundsätzen, ed. Jaeger, Frankfurt/M. 1984.

HEIDEGGER, Martin (GA 56/57) Die Idee der Philosophie und das Weltanschauungsproblem (Kriegsnotsemester 1919), en: Zur Bestimmung der Philosophie, ed. B. Heimbüchel, Frankfurt/M. 1987.

HEIDEGGER, Martin (GA 67) Die Überwindung der Metaphysik (1938/39), en: Metaphysik und Nihilismus, ed. H,-J. Friedrich, Frankfurt/M. 1999.

HEIDEGGER, Martin (Kant-Seminar), Übungen über Kants Kritik der reinen Vernunft und praktischen Vernunft (Transzendentale Dialektik) - Freiburg, WS 1931-32. Typoskript wortgetreue Transkription der handschriftlichen Seminarnotizen von Heideggers Lehrveranstaltung: Übungen..., Herbert-Marcuse-Archiv der Stadt- und Universitätsbibliothek in Frankfurt/M. [Ref. 0028.01], 21 Blätter.

HEIDEGGER, M. y RICKERT, H. (2002), Briefe 1921 bis 1933 und andere Dokumente, ed. A. Denker, Frankfurt/M.

HEIMSOETH, Heinz (1966 ss.), Transzendentale Dialektik. Ein Kommentar zu Kants Kritik der reinen Vernunft, 4 vols., Berlin. 
HENRICH, Dieter (1960), Der ontologische Gottesbeweis. Sein Problem und seine Geschichte in der Neuzeit, Tübingen.

HENRICH, Dieter (1955), “Über die Einheit der Subjektivität”, Philosophische Rundschau, vol. 3; pp. 28-69.

VON HERRMANN, Friedrich-Wilhelm (1991), Heideggers 'Grundprobleme der Phänomenologie'. Zur 'zweiten Hälfte' von 'Sein und Zeit', Frankfurt/M.

HINSKE, Norbert (1998), Zwischen Aufklärung und Vernunftkritik. Studien zum Kantschen Logikcorpus, Stuttgart-Bad Cannstatt.

HOLZHEY, Helmut (1981), “Das philosophische Realitätsproblem. Zu Kants Unterscheidung von Realität und Wirklichkeit”, en: J. Kopper / W. Marx (eds.), 200 Jahre Kritik der reinen Vernunft, Hildesheim; pp. 79-111.

JANSSEN, Paul (1987), "Begriff, Wahrnehmung und Daseinsthesis. Kant und Frege”, Zeitschrift für philosophische Forschung, vol. 41; pp. 229-244.

KANT, Immanuel (AA), Kant's Gesammelte Schriften (Akademie-Ausgabe), Berlin 1900 ss.

KANT, Immanuel, Kritik der reinen Vernunft, ed. R. Schmidt (Philosophische Bibliothek, Bd. 37a), Hamburg 1956.

KANT, Immanuel (MP), Metaphysik Pölitz: Immanuel Kant's Vorlesungen über die Metaphysik, ed. K. H. L. Pölitz, Erfurt 1821 (fotomechanischer Nachdruck, Darmstadt 1964).

KLEIN, Ted (1973), “Being as Ontological Predicate: Heidegger's Interpretation of Kant's Thesis about Being”, Southwestern Journal of Philosophy, vol. 4; pp. 35-51.

KNÜFER, Carl (1911), Grundzüge der Geschichte des Begriffs ‘Vorstellung’ von Wolff bis Kant. Ein Beitrag zur Geschichte der philosophischen Terminologie, Halle/S.

DE LARA, Francisco (2008), Phänomenologie der Möglichkeit. Grundzüge der Philosophie Heideggers 1919-1923, Freiburg/München.

MARTÍNEZ MARZOA, Felipe (2004), “Kant y las inhibiciones lectoras de Heidegger”, Agora. Papeles de filosofía, vol. 23; pp. 149-160.

MEIER, Georg Friedrich, Auszug aus der Vernunftlehre, Halle 1752. (Citado como Auszug)

NEUMANN, Hardy (2003), Die neue Seinsbestimmung in der reinen theoretischen Philosophie Kants: Das Sein als Position (Philosophische Schriften, Bd. 63), Berlin.

PEREGO, Vittorio (2001), Finitezza e libertà. Heidegger interprete di Kant, Milano.

REBERNIK, Pavel (2006), Heidegger interprete di Kant. Finitezza e fondazione della metafisica, Pisa.

REISINGER, Klaus (1992), “Über Kants Diktum: Sein ist kein reales Prädikat”, en: B. Niemeyer / D. Schütze (eds.), Philosophie der Endlichkeit, Würzburg; pp. 27-82.

SALLIS, John (1976), "Radical Phenomenology and Fundamental Ontology", Research in Phenomenology, vol. 6; pp. 139-149.

SCHOPENHAUER, Arthur (2000), Crítica de la filosofía kantiana. Apendice a 'El mundo como voluntad y representación’, trad. P. López de Santa María, Madrid.

STOLZENBERG, Jürgen (2001), "Personalitas moralis. Zu Martin Heideggers Kritik von Kants Theorie des moralischen Bewusstseins”, en: V. Gerhardt/R.P. Horstmann/R. Schumacher (eds.), Kant und die Berliner Aufklärung. Akten des IX. Internationalen Kant-Kongresses, vol. 5, Berlin; pp. 609-618.

TAMINIAUX, Jacques (1989), "La Thèse de Kant sur l'etre et la phénomenologie de la perception”, en: id., Lectures de l'ontologie fondamentale. Essais sur Heidegger, Grenoble; pp. 89-145.

VOLPI, Franco (1984) “Soggetività e temporalità: considerationi sull’interpretazione heideggeriana di Kant alla luce delle lezioni di Marburgo”, en: G. Michele / G. Santillo (eds.), Kant a due secoli della „Critica“, Brescia; pp. 161-179. 
WOLFF, Christian, Prima philosophia sive Ontologia, methodo scientifica pertactata, qua omnis cognitionis humanae principia continentur (1. Aufl.: 1730), ed. J. École, Gesammelte Werke, vol. II/3, Hildesheim 1962. (Citado como Ontologia)

WOLFF, Christian Vernünfftige Gedancken von Gott, der Welt und der Seele des Menschen, auch allen Dingen überhaupt (1. Aufl.: 1720), ed. Ch. A. Corr, Gesammelte Werke, vol. I/2, Hildesheim /Zürich/N.Y. 1983. (Citado como Deutsche Metaphysik) 